\title{
ANALISIS PENGARUH PENYEKATAN KANAL UNTUK PEMBASAHAN LAHAN GAMBUT TROPIS
}

\author{
Gina Khusnul Khotimah ${ }^{1}$, Sigit Sutikno ${ }^{2 *}$, Muhamad Yusa ${ }^{2}$, Indradi Wijatmiko ${ }^{3}$ \\ ${ }^{1}$ Mahasiswa Jurusan Teknik Sipil, Fakultas Teknik, Universitas Riau \\ 2Dosen Jurusan Teknik Sipil, Fakultas Teknik, Universitas Riau \\ 3 Dosen Jurusan Teknik Sipil, Fakultas Teknik, Universitas Brawijaya \\ Korespondensi: sigit.sutikno@lecturer.unri.ac.id
}

\begin{abstract}
Peatlands rewetting for hydrological restoration plays an important role for fire prevention and peatland restoration of degraded peatland. One of the methods for the rewetting is canal blocking. The impact of canal blocking for peatland rewetting is further analyzed in this research. This study focused in Pulau Tebing Tinggi peatland hydrological unit (PHU), which is located in Kepulauan Meranti Regency, Riau Province. To analysis the rewetting impact, 15 dipwells were installed with the distance of $1 \mathrm{~m}, 51 \mathrm{~m}, 101 \mathrm{~m}, 201$ and $301 \mathrm{~m}$ from the canal for each transect of the three transects. A transect was set in the downstream and two transects were set in the upstream of canal block. The ground water level (GWL) in the 15 dipwells was recorded using water-loggers for one year. This research found that canal blocking has a good effect on maintaining groundwater levels and keeping peatlands in always wet or humid conditions up to a distance of $201 \mathrm{~m}$ perpendicular to the canal if the rise in water level in the canal due to canal blocking is more than 0.6 $m$. It is able to maintain the ground water depth in peatlands around $0.4 \mathrm{~m}$, where the peatlands become low risk to the fire, emission rates and subsidence.
\end{abstract}

Kata Kunci : canal blocking, ground water level, tropical peatland

\section{PENDAHULUAN}

Gambut tropis di Indonesia saat ini sudah mengalami degradasi dengan berbagai tingkatan. Degradasi lahan gambut di Indonesia telah terjadi dalam skala besar, sehingga hanya tersisa kurang dari 4\% dari lahan gambut yang masih asli (Pristine Peat Swamp Forest), sementara $37 \%$ lainnya sudah mengalami degradasi dengan berbagai tingkatan degradasi. Selanjutnya, lebih dari $20 \%$ dalam kondisi sebagai lanskap terdegradasi yang tidak dikelola, ditumbuhi pakis, semak dan tumbuhan sekunder[1]. Mengingat kondisi ini, pemerintah Indonesia berusaha merestorasi lahan gambut dengan membentuk badan khusus yang bertugas menangani hal ini, yaitu Badan Restorasi Gambut (BRG) berdasarkan Peraturan Presiden Nomor 1 Tahun 2016. BRG bertugas melakukan restorasi di 7 provinsi prioritas, yakni Sumatera Selatan, Riau, Jambi, Kalimantan Barat, Kalimantan Tengah,
Kalimantan Selatan, dan Papua dengan target restorasi sekitar 2 juta hektar dalam waktu 2016 - 2020 [2]. Provinsi Riau yang memiliki lahan gambut terluas di Indonesia merupakan provinsi paling prioritas untuk direstorasi.

$\begin{array}{ccr}\text { Provinsi } & \text { Riau setiap tahunnya } \\ \text { mengalami kebakaran } & \text { lahan yang }\end{array}$ menyebabkan degradasi secara terus menerus. Menurut pemantauan citra satelit terra/aqua yang tercatat di Provinsi Riau pada tahun 2016 ada 891 titik panas, tahun 2017 ada 81 titik panas, tahun 2018 ada 694 titik panas, dan tahun 2019 sampai dengan bulan Juli 2019 ada 601 titik panas. Titik panas kebakaran lahan gambut di Provinsi Riau ini tersebar di seluruh wilayah, salah satunya adalah di Kabupaten Kepulauan Meranti.

Kebakaran yang terjadi di lahan gambut sangat sulit dipadamkan, karena terjadinya kebakaran di bawah permukaan tanah. Sejarah membuktikan bahwa, jika kebakaran lahan gambut sudah cukup parah, maka hanya hujan 
yang bisa memadamkannya [3]. Oleh karena itu, upaya pencegahan merupakan jalan terbaik untuk menjaga lahan gambut dari ancaman kebakaran. Untuk meminimalkan kebakaran lahan gambut tropis tersebut, BRG Republik Indonesia melakukan program pembasahan lahan gambut dengan pembuatan sekat kanal. Dampak penyekatan kanal untuk pembasahan dan pencegahan kebakaran lahan gambut selama ini masih banyak yang mempertanyakan efektivitasnya. Beberapa penelitian untuk mengkaji pengaruh penyekatan kanal sudah dilakukan, namun masih dilakukan pada durasi yang pendek sehingga dampak perbedaan musim masih belum diakomodir [4]. Seberapa jauh dampak penyekatan kanal terhadap pembasahan lahan gambut dianalisis lebih lanjut dalam penelitian ini. Penelitian dilakukan pada Kesatuan Hidrologis Gambut (KHG) Pulau Tebing Tinggi yang terletak di Kabupaten Kepulauan Meranti, Provinsi Riau.

Untuk mengkaji dampak penyekatan kanal pada lahan gambut, dibuat 15 sumur pantau yang dibagi dalam 3 transek untuk memonitor fluktuasi TMA (Tinggi Muka Air tanah). Monitoring TMA dilakukan mulai dari sebelum penyekatan kanal hingga setelahnya. Dampak penyekatan kanal dikaji berdasarkan data monitoring tersebut.

\section{TINJAUAN PUSTAKA}

\subsection{Lahan Gambut Tropis di Indonesia}

Berdasarkan definisi legal di Indonesia, gambut diartikan sebagai material organik yang terbentuk secara alami dari sisa-sisa tumbuhan yang terdekomposisi tidak sempurna dengan ketebalan 50 (lima puluh) centimeter atau lebih dan terakumulasi pada rawa (PP 57/2017; Permenhut No. 16/2017). Lahan gambut pada umumnya terletak antara 2 sungai besar. meskipun disebut datar, lahan gambut rawa ini umumnya berbentuk kubah (dome). Sehingga terdapat beda ketinggian (elevation). Dalam kondisi tertentu memungkinkan terjadi pergerakan air dari puncak dome ke pinggir sungai. Pergerakan air inilah yang memungkinkan ekosistem rawa bergambut dapat menunjang kehidupan. Karakteristik geografi semacam itu berhubungan erat dengan karakteristik vegetasi hutan yang tumbuh di atasnya.

Indonesia memiliki wilayah lahan gambut tropis terbesar di dunia, yang meliputi sekitar $50 \%$ dari total lahan gambut tropis dunia. Luas lahan gambut di Indonesia diperkirakan sekitar 14,91 juta hektar yang tersebar di Pulau Sumatra 6,44 juta hektar (43\%), di Pulau Kalimantan 4,78 juta hektar (32\%), dan 3,69 juta hektar di Pulau Papua (25\%) [5]. Lahan gambut tropis saat ini menjadi isu global dalam kaitannya dengan penggunaan skala besar untuk berbagai keperluan yang dapat menyebabkan masalah lingkungan termasuk kebakaran lahan, penurunan fungsi ekosistem yang masif, dan peningkatan emisi karbon [6]. Kebakaran lahan gambut tropis sangat sulit dipadamkan, karena kejadian kebakaran lahan gambut terjadi di bawah permukaan yang hanya dapat dipadamkan dengan adanya hujan atau hujan buatan [7] [8].

\subsection{Restorasi Lahan Gambut}

Restorasi lahan gambut merupakan usaha untuk mengembalikan fungsi ekosistem gambut ke kondisi alamiahnya, sehingga fungsi ekosistem gambut bisa kembali mendekati fungsinya semula. Lahan gambut yang terdegradasi masih memiliki potensi untuk dikembalikan ke kondisi dan fungsi semula yang selalu basah dan tertutup vegetasi melalui usaha restorasi gambut [9].

Dalam usaha percepatan restorasi lahan gambut di Indonesia yang sangat luas, maka pemerintah Indonesia membentuk badan yang khusus menangani restorasi gambut, yaitu Badan Restorasi Gambut Republik Indonesia (BRG-RI). Badan non-struktural yang berada di bawah dan bertanggung jawab kepada Presiden ini, diberikan tugas pokok dan fungsi untuk mengkoordinasi dan memfasilitasi kegiatan restorasi gambut di 7 (tujuh) provinsi, yakni Riau, Jambi, Sumatera Selatan, Kalimantan Barat, Kalimantan Tengah, Kalimantan Selatan dan Papua. Usaha restorasi lahan gambut dilakukan melalui pendekatan 3-R, yaitu program pembasahan kembali (re-wetting), penanaman kembali (re-vegetation), dan revitalisasi mata pencaharian (re-vitalization of livelihood) [2].

\subsection{Pembasahan Kembali Lahan Gambut dengan Sekat Kanal}

Tujuan pembasahan kembali lahan gambut yang mengalami degradasi dan kekeringan berlebihan ini yaitu untuk memulihkan fungsi hidrologi gambut yang terlihat dari stabilisasi muka air di lahan 
gambut, meningkatkan kelembaban dan membasahi gambut. Adapun manfaat pembasahan kembali gambut ini adalah sebagai berikut [2]:

1) percepatan proses restorasi gambut,

2) berkurangnya risiko kebakaran lahan dan hutan gambut,

3) berkurangnya laju penurunan/degradasi tanah gambut (land subsidence),

4) berkurangnya laju emisi gas rumah kaca (greenhouse gases emissions), dan

5) terpulihkannya fungsi hidrologis lahan gambut.

Pembasahan kembali (rewetting) pada kawasan gambut yang terdegradasi dapat memberikan keuntungan dalam rehabilitasi dan bisa menjaga kebasahan lahan gambut [4]. Gambut yang basah dapat menghambat terjadinya kebakaran di sekitar 20-30 cm dari permukaan. Usaha pembasahan kembali lahan gambut dengan menutup kanal dicatat memberikan hasil terjadinya penurunan titik api kebakaran gambut yang sangat signifikan pada kebakaran awal 2015 [10].

\section{METODOLOGI PENELITIAN \\ 3.1 Lokasi Penelitian}

Penelitian ini dilakukan di KHG Pulau Tebing Tinggi, Kabupaten Kepulauan Meranti, Provinsi Riau dengan lokasi demplot di Desa Lukun, Kecamatan Tebing Tinggi Timur, seperti pada Gambar 1. KHG Pulau Tebing Tinggi yang $94 \%$ areanya merupakan lahan gambut, merupakan salah satu KHG prioritas untuk direstorasi oleh BRG-RI.

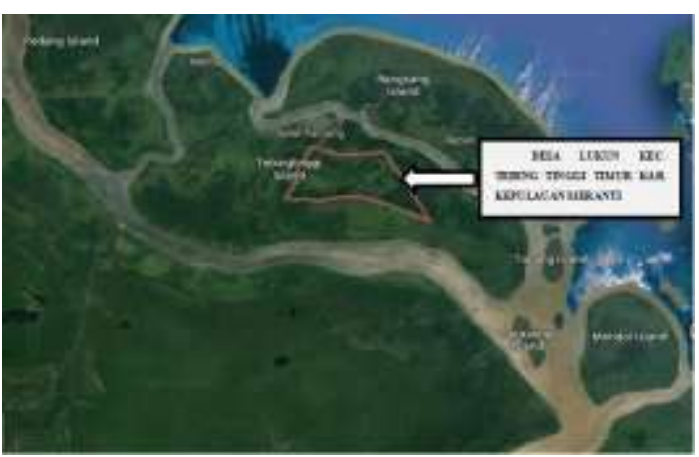

Gambar 1. Lokasi Penelitian sumber: Google Maps, 2019 area yang kanalnya dilakukan penyekatan. Untuk itu dibuat 15 unit sumur pantau yang dibagi dalam 3 transek yang masing-masing transek terdiri atas 5 sumur pantau, untuk pemantauan fluktuasi TMA baik saat sebelum maupun sesudah penyekatan kanal. Jarak masing-masing sumur pantau dari kanal adalah $1 \mathrm{~m}, 51 \mathrm{~m}, 101 \mathrm{~m}, 201 \mathrm{~m}$, dan $301 \mathrm{~m}$, seperti ditunjukkan pada Gambar 2. Transek-1 terletak di lokasi paling hulu yang berjarak 100 meter dari sekat kanal-2 yang berada di hilirnya. Transek-2 terletak 200 meter sisi hilir dari Sekat Kanal-2 dan 100 meter sisi hulu Sekat Kanal-3. Sedangkan Transek-3 terletak di 100 meter bagian hilir dari Sekat Kanal-3, yang merupakan transek paling hilir.

Pencatatan fluktuasi TMA dilakukan dengan menggunakan 8 alat water logger dengan interval 1 jam, sedangkan 7 sumur pantau yang lain diukur secara manual setiap 2 minggu sekali. Lokasi sumur pantau yang diukur baik secara manual maupun otomatis seperti disajikan pada Gambar 2.

Pada Gambar 3 ditunjukkan model sekat kanal yang dibuat di lokasi penelitian, dengan struktur sekat kanal terbuat dari kayu yang digabung dengan bahan pengisi berupa karung tanah. Seperti disajikan Pada Gambar 2, ada 3 unit sekat kanal yang dibangun pada masa penelitian sedang berlangsung, yaitu tanggal 15 November 2018.

Sedangkan pada Gambar 4 ditunjukkan alat water logger yang dipakai untuk merekam fluktuasi TMA secara otomatis pada penelitian ini. Perekaman fluktuasi TMA dilakukan pada kurun waktu tanggal 30 Oktober 2018 sampai dengan 10 November 2019.

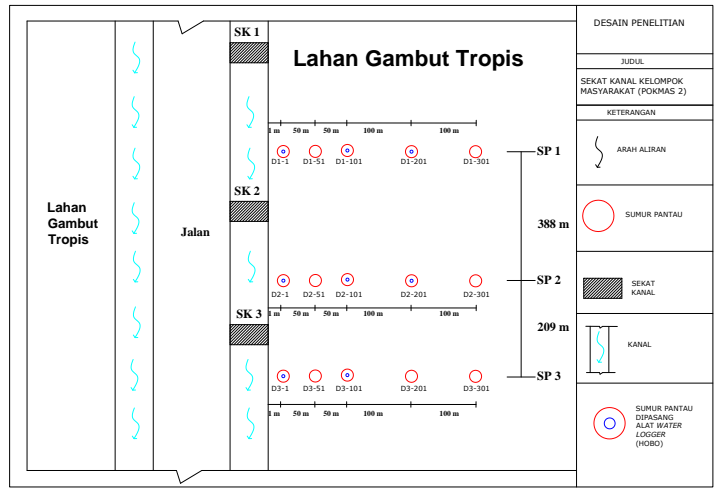

Gambar 2. Desain Penelitian

\subsection{Desain Penelitian}

Dampak pembasahan lahan gambut dimonitor dengan adanya kenaikan TMA di 


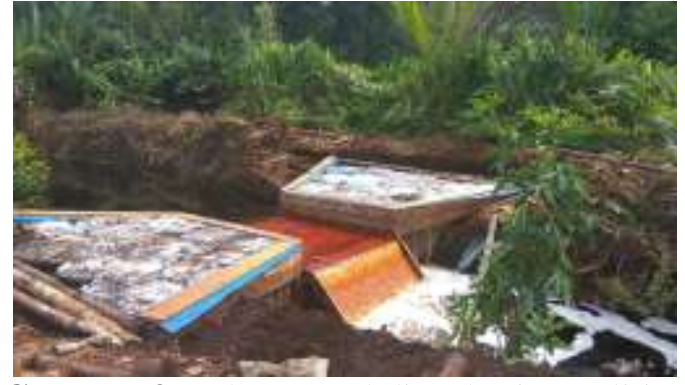

Gambar 3. Sekat Kanal di Lokasi Penelitian

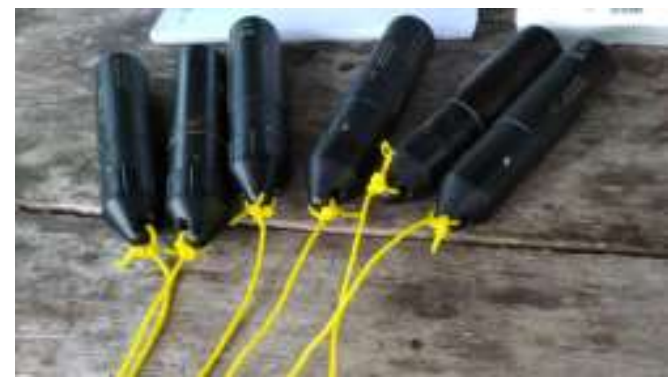

Gambar 4. Alat Water Logger untuk

Pemantauan TMA Secara Otomatis

\section{HASIL DAN PEMBAHASAN}

Data hasil pencatatan fluktuasi TMA pada kurun waktu tanggal 30 Oktober 2018 sampai dengan 10 November 2019 dianalisis untuk mengkaji dampak pembasahan akibat penyekatan kanal. Pembahasan dilakukan tiap transek pemantauan dan elevasi TMA setelah penyekatan.

\subsection{Transek pertama}

Pada Gambar 5 disajikan hubungan antara kenaikan TMA pada sumur pantau Transek-1 yang berjarak $1 \mathrm{~m}$ dari kanal dengan kenaikan TMA pada sumur pantau yang berjarak $101 \mathrm{~m}$ dari kanal. Sedangkan hubungan kenaikan TMA pada jarak $1 \mathrm{~m}$ dari kanal dengan kenaikan TMA pada jarak $201 \mathrm{~m}$ dari kanal disajikan pada Gambar 6.

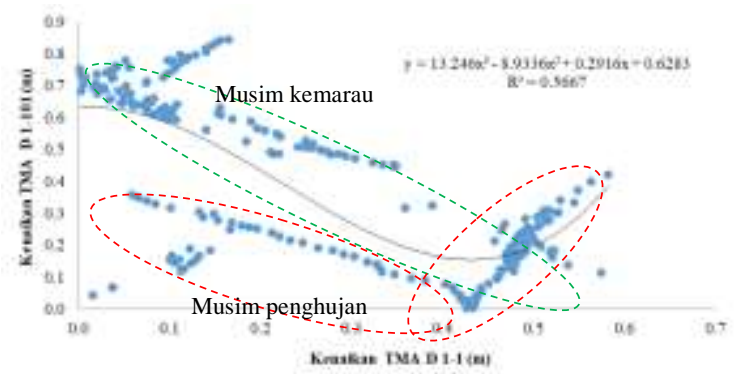

Gambar 5. Hubungan Kenaikan TMA pada sumur pantau Transek-1 berjarak 1 m dan 101 m dari kanal
Seperti ditunjukkan pada Gambar 5, di saat musim penghujan fluktuasi TMA di lahan gambut pada Transek-1 yang berjarak $101 \mathrm{~m}$ dari kanal berfluktuasi baik disebabkan oleh adanya curah hujan maupun oleh karena penyekatan kanal. TMA di lahan gambut yang berjarak $101 \mathrm{~m}$ dari kanal akan terus meningkat ketika terjadi kenaikan TMA di kanal (sumur pantau yang berjarak $1 \mathrm{~m}$ dari kanal) $0.5 \mathrm{~m}$ atau lebih, seperti ditunjukkan pada Tabel 1. Artinya bahwa, TMA di lahan gambut yang berjarak $101 \mathrm{~m}$ dari kanal akan terdampak oleh penyekatan kanal jika sekat kanal bisa menaikan elevasi air di kanal minimal $0.5 \mathrm{~m}$.

Di saat musim kemarau, TMA di lahan masih tetap tinggi walaupun di kanal sudah mulai berkurang akibat evaporasi. Penurunan TMA di kanal dan di lahan terus terjadi karena evaporasi, namun di kanal lebih cepat terjadi. Penyusutan yang terjadi dominan oleh aliran dan evaporasi. Ketika aliran di kanal sudah tidak ada karena sudah tidak tercukupi oleh hujan, maka akan dominan kehilangan air oleh evaporasi. Kecepatan evaporasi di kanal lebih besar dibanding dengan di lahan sehingga penurunan TMA di kanal lebih cepat dari pada di lahan. Air di lahan tetap terjaga dengan baik karena pengatusannya berjalan lebih lambat dari pada di kanal.

Nilai koefisien determinasi $\left(\mathrm{R}^{2}\right)$ menunjukkan bahwa, persentase akibat penyekatan kanal, dimana kenaikan TMA dilahan pada jarak $1 \mathrm{~m}$ adalah 56,67\% akan mempengaruhi kenaikan TMA dilahan pada jarak $101 \mathrm{~m}$.

Fenomena fluktuasi TMA yang terjadi di lahan gambut pada Transek-1 yang berjarak $201 \mathrm{~m}$ mirip dengan yang terjadi di lahan gambut yang berjarak $101 \mathrm{~m}$, seperti disajikan pada Gambar 6. Perbedaannya adalah pada dampak kenaikan TMA akibat penyekatan kanal yang semakin kecil. Sebagai contoh, kenaikan TMA pada kanal (sumur pantau berjarak $1 \mathrm{~m}$ dari kanal) sebesar $0.5 \mathrm{~m}$ akibat penyekatan kanal, akan menyebabkan kenaikan TMA pada lahan yang berjarak $101 \mathrm{~m}$ dan 201 $\mathrm{m}$ dari kanal adalah masing-masing $0.20 \mathrm{~m}$ dan $0.14 \mathrm{~m}$, seperti ditunjukkan pada Tabel 1 . Nilai koefisien determinasi $\left(\mathrm{R}^{2}\right)$ pada fluktuasi TMA yang berjarak $201 \mathrm{~m}$ juga menunjukkan nilai yang tidak jauh berbeda, yaitu 57,43\%.

Berdasarkan Tabel 1, kedalaman TMA di lahan yang berjarak $101 \mathrm{~m}$ dan $201 \mathrm{~m}$ akan mencapai 0.4 m, jika kenaikan TMA di kanal 
minimal 0.6. Kondisi tersebut adalah kondisi aman pada lahan gambut dari risiko kebakaran, karena risiko kebakaran lahan gambut jadi kecil jika kedalamannya minimal $0.4 \mathrm{~m} \mathrm{[11]} \mathrm{[12].}$

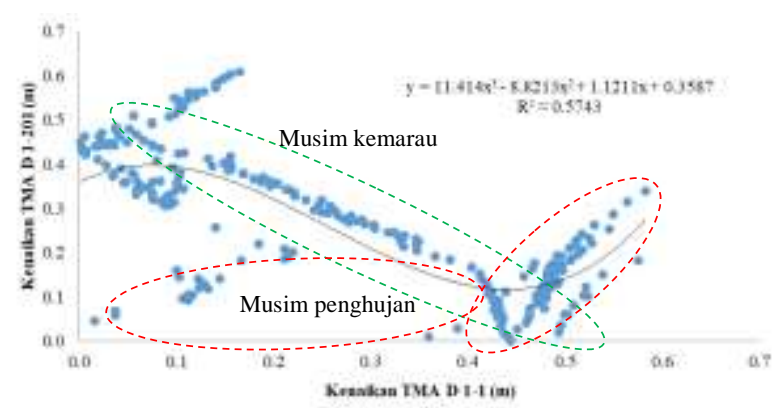

Gambar 6. Hubungan Kenaikan TMA Pada Sumur Pantau Transek-1 Berjarak 1 m dan 201 m Dari Kanal

Tabel 1. Fluktuasi Kenaikan TMA Pada

Transek-1

\begin{tabular}{|c|c|c|c|c|}
\hline \multirow{3}{*}{$\begin{array}{c}\text { Kenaikan } \\
\text { TMA D } \\
1-1 \text { (m) }\end{array}$} & \multicolumn{2}{|c|}{ D $1-101$} & \multicolumn{2}{|c|}{ D 1-201 } \\
\hline & $\overline{\text { Kenaikan }}$ & Kedalaman & Kenaikan & Kedalaman \\
\hline & TMA (m) & $(\mathrm{m})$ & TMA (m) & (m) \\
\hline 0.40 & 0.16 & 0.69 & 0.13 & 0.59 \\
\hline 0.45 & 0.16 & 0.69 & 0.12 & 0.60 \\
\hline 0.50 & 0.20 & 0.65 & 0.14 & 0.58 \\
\hline 0.55 & 0.29 & 0.56 & 0.21 & 0.52 \\
\hline 0.60 & 0.45 & 0.40 & 0.32 & 0.40 \\
\hline
\end{tabular}

\subsection{Transek Kedua}

Pada Gambar 7 disajikan hubungan antara kenaikan TMA pada sumur pantau Transek-2 yang berjarak $1 \mathrm{~m}$ dari kanal dengan kenaikan TMA pada sumur pantau yang berjarak $101 \mathrm{~m}$ dari kanal. Sedangkan hubungan kenaikan TMA pada jarak $1 \mathrm{~m}$ dari kanal dengan kenaikan TMA pada jarak $201 \mathrm{~m}$ dari kanal disajikan pada Gambar 8.

Hasil monitoring fluktuasi TMA di Transek-2 menunjukkan kecenderungan yang hampir sama dengan yang terjadi di Transek-1, seperti ditunjukkan pada Gambar 7 dan Gambar 8. Perbedaannya adalah, bahwa pada Transek-2 diperlukan menaikkan $0.55 \mathrm{~m}$ pada TMA di kanal supaya lahan gambut yang berjarak $101 \mathrm{~m}$ dan $201 \mathrm{~m}$ tetap terjaga di kedalaman $0.4 \mathrm{~m}$ (kedalaman TMA yang aman terhadap risiko kebakaran gambut) seperti ditunjukkan pada Tabel 2. Kenaikan ini adalah $5 \mathrm{~cm}$ lebih rendah dari yang terjadi di Transek-1. Jika pada Transek-2 dinaikkan TMA di kanalnya setinggi 0.6 , maka lahan gambut yang berjarak $101 \mathrm{~m}$ dan $201 \mathrm{~m}$ akan lebih basah dari yang terjadi di Transek-1 karena TMAnya lebih dangkal yaitu $0.36 \mathrm{~m}$ dan $0.26 \mathrm{~m}$. Hal ini terjadi karena lahan gambut pada Transek-2 mengalami dampak pembasahan tidak hanya dari Sekat Kanal-3, namun juga dari Sekat Kanal-2. Akibat adanya Sekat Kanal 2 yang membasahi lahan gambut pada Transek-1, air tanah juga mengalir ke Transek-2 karena perbedaan energi potensial dan menyebabkan TMA di Transek-2 semakin tinggi [13].

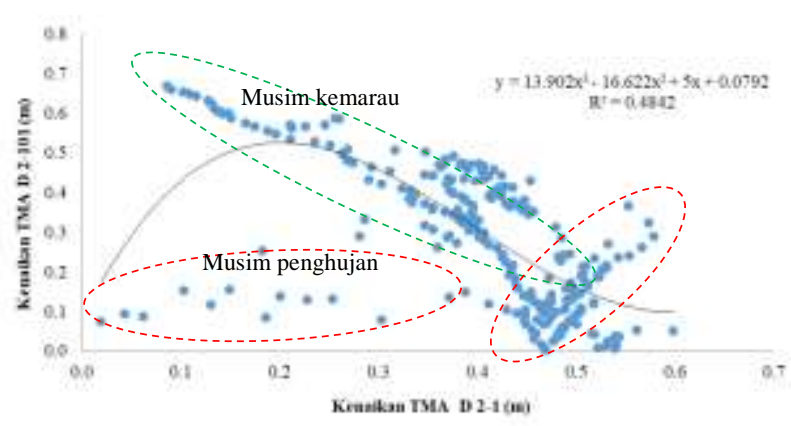

Gambar 7. Hubungan Kenaikan TMA Pada Sumur Pantau Transek-2 Berjarak 1 m dan 101 m Dari Kanal

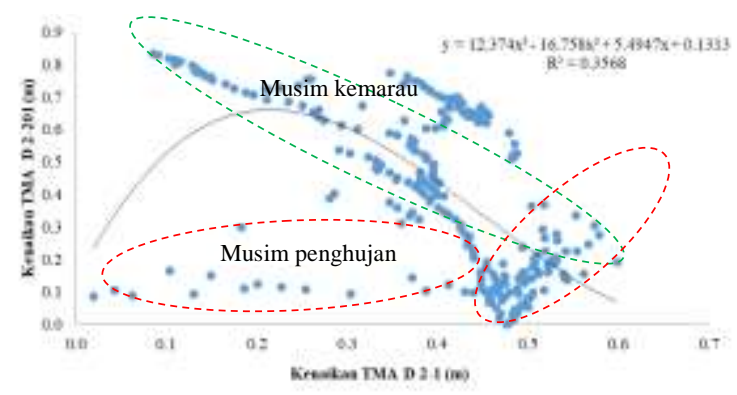

Gambar 8. Hubungan Kenaikan TMA Pada Sumur PAntau Transek-2 Berjarak 1 m dan 201 m dari Kanal

Tabel 2. Fluktuasi Kenaikan TMA Pada Transek-2

\begin{tabular}{|c|c|c|c|c|}
\hline \multirow{2}{*}{$\begin{array}{c}\text { Kenaikan } \\
\text { TMA D } \\
2-1(\mathrm{~m})\end{array}$} & \multicolumn{2}{|c|}{ D $2-101$} & \multicolumn{2}{|c|}{ D 2-201 } \\
\hline & $\begin{array}{l}\text { Kenaikan } \\
\text { TMA (m) }\end{array}$ & $\begin{array}{c}\text { Kedalaman } \\
(\mathrm{m})\end{array}$ & $\begin{array}{l}\text { Kenaikan } \\
\text { TMA (m) }\end{array}$ & $\begin{array}{c}\begin{array}{c}\text { Kedalaman } \\
(\mathrm{m})\end{array} \\
\end{array}$ \\
\hline 0.40 & 0.11 & 0.63 & 0.12 & 0.57 \\
\hline 0.45 & 0.11 & 0.63 & 0.12 & 0.57 \\
\hline 0.50 & 0.17 & 0.58 & 0.18 & 0.51 \\
\hline 0.55 & 0.25 & 0.49 & 0.28 & 0.41 \\
\hline 0.60 & 0.38 & 0.36 & 0.43 & 0.26 \\
\hline
\end{tabular}

\subsection{Transek Ketiga}

Pada Transek-3, yang merupakan transek paling hilir memiliki korelasi yang berbeda seperti yang terjadi pada Transek-1 dan Transek 2, seperti ditunjukkan pada Gambar 9. Hal ini terjadi karena pada Transek-3 tidak 
dipengaruhi oleh penyekatan kanal yang dilakukan pada bagian hulu. Fluktuasi TMA di lahan gambut mengikuti fluktuasi TMA di kanal. Jika TMA di kanal tinggi maka TMA di lahan gambut juga tinggi, sebaliknya jika TMA di kanal rendah maka TMA di lahan juga rendah yang mengikuti ketersediaan air hujan. Artinya bahwa fluktuasi TMA di lahan gambut yang tidak ada penyekatan kanal hanya tergantung pada curah hujan yang berfluktuasi secara musiman. Perbedaan karakteristik fluktuasi TMA di lahan gambut yang terjadi di Transek-1 dan Transek-2 dengan di Transek-3 merupakan dampak dari adanya penyekatan kanal.

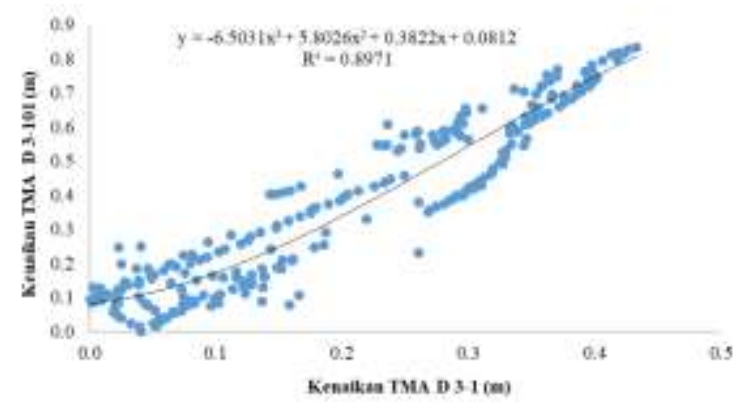

Gambar 9. Hubungan Kenaikan TMA pada sumur pantau Transek-3 berjarak 1 m dan 101 m dari kanal

\section{KESIMPULAN DAN SARAN}

Hasil penelitian ini menunjukkan bahwa penyekatan kanal memiliki dampak yang baik untuk menjaga ketinggian air tanah dan menjaga lahan gambut pada kondisi selalu basah atau lembab hingga jarak $201 \mathrm{~m}$ tegak lurus ke kanal jika kenaikan permukaan air di kanal lebih dari 0,6 m. Kenaikan elevasi air di kanal hingga 0,6 m karena penyekatan kanal mampu menjaga kedalaman air tanah di lahan gambut sekitar $0.4 \mathrm{~m}$, dimana pada kedalaman tersebut lahan gambut jadi tidak mudah terbakar, laju emisi dan subsidensinya rendah.

\section{UCAPAN TERIMA KASIH}

Ucapan terima kasih disampaikan kepada Badan Restorasi Gambut Republik Indonesia (BRG-RI) yang telah memfasilitasi penelitian ini. Kegiatan penelitian ini adalah bagian dari penelitian kerja sama antara Universitas Riau dengan BRG-RI.

\section{DAFTAR PUSTAKA}

[1] L. P. Koh, J. Miettinen, S. C. Liew, and J. Ghazoul, "Remotely sensed evidence of tropical peatland conversion to oil palm.," Proc. Natl. Acad. Sci. U. S. A., vol. 108, no. 12, pp. 5127-32, 2011, doi: 10.1073/pnas.1018776108.

[2] A. Dohong et al., Modul pelatihan Pembangunan Infrastruktur Pembasahan Gambut Sekat Kanal Berbasis Masyarakat, no. April. Jakarta: Kedeputian Bidang Konstruksi, Operasi dan Pemeliharaan Badan Restorasi Gambut (BRG), Republik Indonesia, 2017.

[3] A. Sandhyavitri, M. A. Perdana, S. Sutikno, and F. H. Widodo, "The roles of weather modification technology in mitigation of the peat fires during a period of dry season in Bengkalis, Indonesia," in TALENTA-CEST, IOP Conf. Series: Materials Science and Engineering, 2018, pp. 0-9, doi: 10.1088/1757-899X/309/1/012016.

[4] S. Sutikno et al., "The effectiveness of canal blocking for hydrological restoration in tropical peatland," MATEC Web Conf., vol. 6003, no. 276, pp. 1-7, 2019.

[5] M. Osaki and N. Tsuji, Tropical Peatland Ecosystems. Sapporo: Springer Tokyo Heidelberg New york Dordrecht London, 2015.

[6] S. Sabiham, Winarna, H. B. Pulunggono, D. Novarina, and B. Sahari, "What is the way forward on Indonesian Peatland?," in $15 T H$ INTERNATIONAL PEAT CONGRESS 2016, 2016, no. August, pp. 39-45.

[7] A. Sandhyavitri, M. A. Perdana, S. Sutikno, and F. H. Widodo, "The roles of weather modification technology in mitigation of the peat fires during a period of dry season in Bengkalis, Indonesia," IOP Conf. Ser. Mater. Sci. Eng., vol. 309, p. 012016, 2018, doi: 10.1088/1757-899X/309/1/012016.

[8] S. Sutikno, A. Sandhyavitri, A. Syahza, H. Widodo, and T. H. Seto, "Application of weather modification technology for peatlands fires mitigation in Riau, Indonesia," in Proceedings of International Symposium on Advances in Mechanical Engineering (ISAME): Quality in Research 2019, 2020, no. May, doi: 10.1063/5.0002137.

[9] S. E. Page, J. O. Rieley, and C. J. Banks, "Global and regional importance of the tropical peatland carbon pool," Glob. Chang. Biol., vol. 17, no. 2, pp. 798-818, 2011, doi: 10.1111/j.1365-2486.2010.02279.x.

[10] E. I. Putra et al., "Developing better understanding on tropical peat fire occurrences 
and dynamics," IOP Conf. Ser. Earth Environ. Sci., vol. 394, no. 1, 2019, doi: 10.1088/1755-1315/394/1/012044.

[11] H. Pratama, S. Sutikno, and M. Yusa, "Modeling of groundwater level fluctuation in the tropical peatland area of Modeling of groundwater level fluctuation in the tropical peatland area of Riau, Indonesia," IOP Conf. Ser. Mater. Sci. Eng., vol. 796, no. 012037, pp. $1-8$, 2020 ,

doi: 10.1088/1757-899X/796/1/012037.

[12] S. H. Silviana, B. H. Saharjo, and S. Sutikno, "Fire risk analysis based on groundwater level in rewetting peatland, Sungaitohor village , kepulauan Meranti district, Riau province Fire risk analysis based on groundwater level in rewetting peatland, Sungaitohor village , kepulauan Meranti district ," IOP Conf. Ser. Mater. Sci. Eng., vol. 796, no. 012037, pp. 1-8, 2020, doi: 10.1088/1757-899X/796/1/012041.

[13] S. Sutikno, R. D. Ramawilis, F. A. Hutapea, and K. Yamamoto, "Application of paper disc velocimeter for groundwater flow measurement in tropical peatland Application of paper disc velocimeter for groundwater flow measurement in tropical peatland," IOP Conf. Ser. Mater. Sci. Eng., vol. 796, no. 012037, pp. 1-8, 2020, doi: $10.1088 / 1757-899 X / 796 / 1 / 012042$. 